\title{
Cross-Cultural Study of Historical Effects on Emotional Intelligence Among Young Adults
}

\author{
Makhinur Mamatova \\ American University of Central Asia, Bishkek, Kyrgyz Republic \\ Diane E. Wille \\ Indiana University Southeast, New Albany, United States
}

\begin{abstract}
This study investigates historical and cultural effects on one component of emotional intelligence, the ability to recognize and report on one's emotions. This study suggests a novel influence on emotional intelligence, an individual's historical context. Samples of young adults, from Kyrgyzstan, former Soviet Republic in Central Asia, and the USA were assessed using the Toronto Alexithymia Scale (TAS-20) (Bagby, Parker, \& Taylor, 1994) in 2002 and again in 2012, and in 2018. Significant historical cohort effect, significant interaction effect, and gender effects were found.
\end{abstract}

Keywords: cross-cultural research, emotional intelligence, alexithymia, young adults, cohort effect

Emotional intelligence is a complex cognitive ability to use emotional information to facilitate problem solving and decision making, establish positive social connections, and maintain healthy emotional self-control. Emotional intelligence is recognized as one of the major determinants of individual ability to succeed in life (Bar-On, 1996; Goleman, 1995; 1998). It contains multiple components including the ability to identify and understand one's own emotions and the emotions of others, and manage them to establish rapport with people to attain personal goals (Mayer, Salovey, \& Caruso, 2008). At present the term "emotional intelligence" has a variety of meanings. However almost all researchers in this field agree that emotional intelligence should be understood as the Four-Branch Model first introduced by Mayer and Salovey in 1997. According to Mayer and Salovey, emotional intelligence represents (1) the ability to perceive emotions in oneself and others; (2) the ability to generate, use, and feel emotion to facilitate thought; (3) the ability to understand emotional information through interpersonal relationships and other social connections; (4) the ability to manage one's own emotions. The growing interest in the study of emotional intelligence contributes to the increasing number of research exploring this phenomenon from different points of view and in diverse contexts. Although the scope of studies cover wide areas of disciplines such as neuroscience (Bechara \& Bar-On, 2006; Jausovec \& Jausovec, 2010; Rolls, 2008; Tarasuik, Ciorciari, \& Stough, 2009), health psychology (Austin, Saklofske, \& Egan, 2005; Day, Therrien, \& Carroll, 2005), psychology of personality (Day, Therrien, \& Carroll, 2005; Keats, Landa, Martos, \& Lopez-Zafra, 2010), and education (Austin, Evans, Goldwater, \& Potter, 2005; Parker,

Makhinur Mamatova, Associate Professor of Psychology, Department of Psychology, American University of Central Asia, Bishkek, Kyrgyz Republic.

Diane E. Wille, Professor of Psychology, Dean for Graduate Studies and Research, Indiana University Southeast, New Albany, United States. 
Summerfeldt, Hogan, \& Majeski, 2004; Saklofske, Austin, Mastoras, Beaton, \& Osborne, 2012), the predominant studies of emotional intelligence and their application concentrate in the field of management (Ahmetoglu, Leutner, \& Chamorro-Premuzic, 2011; Ashkanasy \& Daus, 2002; Blattner \& Bacigalupo, 2007; Bratton, Dodd, \& Brown, 2011) and organizational behavior (Mahon, Taylor, \& Boyatzis, 2014; Miao, Humphrey, \& Qian, 2017; Momm, Blickle, Liu, Wihler, Kholin, \& Menges, 2015; O’Boyle, Humphrey, Pollack, Hawver, \& Story, 2011).

Despite the relevance of the study of emotional intelligence, cross-cultural emotional intelligence research is relatively new. Cross-cultural psychology itself is a fairly new branch of psychology with developing conceptual apparatus. It helps to better understand cultural differences in perception, affect, motivation, and traits as well as explore sustainable universal psychological patterns across cultures. The debate continues on the status of cross-cultural psychology and its place in the methodology of psychological research (Beins, 2011; Cherry, 2012). There are complex conceptual issues in the cross-cultural study of emotional intelligence (Ekermans, 2009). The empirical evidences on culture-related features of emotional intelligence are insufficient (Matthews, Zeidner, \& Roberts, 2002). Meanwhile, cross-cultural studies of emotional intelligence are primarily focused on job performance and work profile (Ali, Garner, \& Magadley, 2012; Apaydin \& Anafarta, 2012) and cross-cultural management (Camuffo, Gerli, \& Gubitta, 2012; Crowne, 2013; Emmerling \& Boyatzis, 2012).

The limited research on the origins of emotional intelligence suggests a link between culture (Dere, Falk, \& Ryder, 2012; Le, Berenbaum, \& Raqhavan, 2002) and components of emotional intelligence. One component of emotional intelligence is the ability to understand, label and verbally express our own emotions and feelings and discriminate among them. Alexithymia is described as the infringement of the ability to recognize and verbally describe one's own emotions (Neimah, Freyberg, \& Sifneos, 1976). The alexithymia construct was formulated by Neimah, Freyberg, and Sifneos (1976) on the basis of clinical observations and is comprised of the following features: (1) difficulty identifying feelings, (2) difficulty describing feelings, (3) limited imagination capacity, and (4) an externally-oriented way of thinking. Salovey and Mayer (1989/1990) view alexithymia as a closely related construct with emotional intelligence. Parker, Bagby, and Taylor (2001) empirically proved that alexithymia and emotional intelligence represent "independent but considerably overlapped and inversely related constructs". Historically alexithymia is rooted to clinical research on somatization of mental tension and chronic anxiety. The research shows that alexithymic characteristics may exist within the context of a normal personality trait profile. The construct of alexithymia was criticized in cultural literature for the westernization of emotional experience and ability to verbalize it (Dion, 1996). Researchers have shown that alexithymia can have a cultural root. The relationship between alexithymia and culture was examined in several cross-cultural studies in college students from three cultural groups: European Americans, Asian Americans, and Malasyans (Le, Berenbaum, \& Raqhavan, 2002). European American students showed lower alexithymia indices than both Asian groups. Cultural examination of alexithymia among Euro-Canadian and Chinese-Canadian students (Dere, Falk, \& Ryder, 2012) revealed cultural difference in externally-oriented thinking. Despite the fact that culture significantly impacts the emotional experiences of individuals and manifestations of personality traits (Ekman, 1972; Hofstede, 1980), emotional intelligence and alexithymia still remain a little-studied phenomena in cross-cultural psychology.

Using a unique design, the current study is one of the first to investigate cultural and historical effects on the alexithymic component of emotional intelligence in two cultures, U.S.A. and Kyrgyzstan, at multiple times. 


\section{Method}

\section{Participants}

In 2002, 39 Kyrgyz and 28 USA young adults completed the Toronto Alexithymia Scale (TAS-20) (Bagby, Parker, \& Taylor, 1994). In 2012 and 2013, 31 young adults in Kyrgyzstan and 41 young adults in the USA completed the TAS-20. In 2018, 40 Kyrgyz and 44 USA young adults completed TAS-20. The demographic information of the samples is provided in Table 1. Analysis of Variance and Chi-Square analysis reveal no significant difference between the Kyrgyz and USA samples on age or gender. The Kyrgyz sample was recruited from a mid-sized university in the capital city of Bishkek, Kyrgyzstan. The USA sample was recruited from a mid-sized university in the Louisville, Kentucky metro area. The predominant ethnic background of the individuals from Kyrgyzstan was Kyrgyz and European American for the sample from the United States. Each sample reflects the major religion of the country; the Kyrgyzstan participants were predominantly Muslim and the United States participants were either Catholic or Protestant.

Table 1

Demographic Information for United States (USA) and Kyrgyzstan (KG) Samples

\begin{tabular}{lllllll}
\hline & \multicolumn{3}{c}{ Phase 1 (2002) } & \multicolumn{2}{c}{ Phase 2 (2012) } & \multicolumn{2}{c}{ Phase 3 (2018) } \\
\cline { 2 - 7 } & USA & KG & USA & KG & USA & KG \\
\cline { 2 - 7 } & $(\mathrm{N}=28)$ & $(\mathrm{N}=39)$ & $(\mathrm{N}=41)$ & $(\mathrm{N}=31)$ & $(\mathrm{N}=44)$ & $(\mathrm{N}=40)$ \\
\hline Age (Mean) & 19.25 & 19.13 & 20.05 & 20.77 & 19.91 & 20.61 \\
\hline Gender & 12 & 21 & 18 & 9 & 17 & 20 \\
\hline Male & 16 & 18 & 23 & 22 & 27 & 20 \\
Female & 16 &
\end{tabular}

Religion: USA sample predominantly Christian; Kyrgyz sample predominantly Muslim.

Note. Analysis of Variance (age) and Chi-Square analysis (gender) revealed nonsignificant differences between Kyrgyz and USA samples.

\section{Instrument}

The 20-Item Toronto Alexithymia Scale TAS-20 (Bagby, Parker, \& Taylor, 1994) is a widely used self-report measure of alexithymia. The TAS-20 consists of 20 items which are rated on a five-point Likert scale ranging from 1 (strongly disagree) to 5 (strongly agree). Items were then summed and averaged to create an alexithymia score for each participant. A higher score indicates less understanding of one's feelings and ability to verbally express feelings and greater alexithymia. The TAS- 20 has been found to be a reliable and valid instrument and has been used widely in diverse cultures (Bagby, Parker, \& Taylor, 1994; Ekermans, 2009; Güleç, Kose, Citak, \& Yazici, 2009; Le, Berenbaum, \& Raghavan, 2002; Parker, Taylor, \& Bagby, 1998; 2003).

\section{Procedure}

Each group of students were administered the assessment in their native/first language. For the participants in Kyrgyzstan it was Russian. For the participants from the USA it was English.

\section{Results}

Two Way Analysis of Variance (ANOVA) was used to investigate differences in ability to understand and verbally express feelings between Kyrgyz and USA young adults at Phase 1 (2002), Phase 2 (2012), and Phase 3 (2018; Table 2). A significant historical cohort effect was found. Participants scored higher on the TAS-20 at 
the first phase. In 2002, both Kyrgyz and USA young adults were less able to understand and verbally express their own feelings than young adults in 2012 and in 2018, $F(2,204)=16.17, p<0.01$. The differences in TAS-20 between Kyrgyz and USA groups and the interaction effect were trends, $F(1,204)=2.94, p<0.10 ; F$ $(2,204)=2.67, p<0.10$, respectively. Post hoc analysis was used to further investigate. In 2002, the Kyrgyz sample alexithymia average score showed a deficiency in identifying own emotions and ability to verbally express them, whereas, American young adults did not report the presence of alexithymic characteristics. In Phase 1 significant differences between the Kyrgyz and USA group were found, $F(1,66)=6.84, p<0.05)$ that were not found in 2012 and 2018. The increase of alexithymia score in Kyrgyz group at Phase 3 did not reach the same degree of alexithymic index nor it was significantly different from the USA young adults.

\section{Table 2}

A Comparison of Kyrgyz and USA Young Adults Scores on the Toronto Alexithymia Scale-20, Phase 1 (2002), Phase 2(2012), and Phase 3 (2018)

\begin{tabular}{llll}
\hline & Phase 1 (2002) & Phase 2 (2012) & Phase 3 (2018) \\
\hline Kyrgyz young adults & 2.99 & 2.40 & 2.62 \\
USA young adults & 2.73 & 2.47 & 2.44 \\
\hline
\end{tabular}

Note. The numbers are averages. Higher score indicates greater inability to understand and verbally express one's own feelings. Participants did not score within the clinical realm of Alexithymia.

Gender effect. Two Way ANOVAs were used to investigate differences between male and female Kyrgyz and USA young adults ability to understand and express emotion (Table 3). A gender difference was found. Males were less able to understand and verbally express their own feelings than females, $F(1,206)=13.54, p$ $<0.01$, overall. An interaction effect was not found.

Table 3

A Comparison of Male and Female Young Adults Scores on the Toronto Alexithymia Scale-20 at Phase 1, Phase 2, and Phase 3

\begin{tabular}{llllllc}
\hline & \multicolumn{3}{c}{ Phase 1 (2002) } & \multicolumn{2}{c}{ Phase 2 (2012) } & \multicolumn{2}{c}{ Phase 3 (2018) } \\
\cline { 2 - 6 } & Male & Female & Male & Female & Male & Female \\
\hline Kyrgyz & 3.08 & 2.89 & 2.64 & 2.24 & 2.74 & 2.53 \\
USA & 2.75 & 2.72 & 2.54 & 2.40 & 2.63 & 2.33 \\
\hline
\end{tabular}

\section{Discussion}

Alexithymia as a lack of access to one's own emotions is the reverse of a description of someone with a high level of emotional intelligence. The nature of alexithymia is still unclear. The existing body of research acknowledges at least three factors that may contribute to the onset of alexithymic characteristics. They are (1) neurobiological factor related to disruption of hemispheric interaction (Meza-Concha, Arancibia, Salas, Behar, Salas, Silva, \& Escobar, 2007); (2) mechanism of defense from distressing emotions (Parker, Taylor, \& Bagby, 1998), and (3) cultural influence as a mechanism of control and emotion suppression (Dere, Falk, \& Ryder, 2012). The results of the current study relate to a cultural determination of alexithymia. The unique design of this research suggests that an individual's historical context serves as a novel influence on emotional intelligence. The effect of historical period emphasizes differences in behavior, cognition, and affect changing over time due to social, cultural, political, economic, and environmental factors.

In the context of this research, historical periods influence cohorts of late adolescents from two different 
cultures resulting in cohort effects. A cohort is a group of people who have experienced the same historic event or the series of events within the same time period (Ryder, 1965). Adolescence to early adulthood is a formative period that determines the future course of life. This time interval significantly affects the cohesiveness of a cohort (Nauen, 2006). Along with cognitive and social development, the adolescent/young adults' emotional development is concentrated on increasing self-awareness, emotional stability, and empathy (Rosenblum \& Lewis, 2006). In this research, the cohort effect describes differences in emotional development shaped by historic contexts. These differences are indicators of dynamic social and cultural change.

The first phase of the research (2002) revealed a significantly higher rate of alexithymia in Kyrgyz participants. The second (2012) and third (2018) phase of the research revealed the striking similarity between the Kyrgyz and U.S. young adults on their ability to understand and verbally express their emotions. There are many possibilities within the historical context to explain these results. Kyrgyzstan is a small Central Asian landlocked country with the population of 6.0 million. It has an ancient history of nomadism, a recent past of Russian colonization and Soviet suppression of ethnic identity. The fall of the former Soviet culture led to unpredictable consequences in the form of two revolutions and changes in the cultural climate of Kyrgyzstan. The surge of Western culture heavily influenced socio-cultural settings and the mindset of young adults. It is important to mention that the Kyrgyz sample of this study consists of students of the American University of Central Asia (AUCA). AUCA is unique and the first in Central Asia to provide an American-style liberal arts education. The university was established in 1993 with the mission to promote Western values of human rights and freedoms. The students of this university are taught academic integrity, academic freedom, critical inquiry, and the value of free self-expression. We assume that educational environment of American University of Central Asia may also affect the dynamics of alexithymia characteristics.

The cohort of 2002 Kyrgyz young adults, born in the era of the late Soviet Union, was heavily influenced by Soviet cultural. We may describe this culture as alexithymic in its nature as it rigidly controlled free expression of emotion, thought, and behavior of individuals. Emotion suppression is a prominent characteristic of Soviet cultural mores. The cohort of 2012 represents a generation that came of age after since the collapse of the Soviet Union. The characteristic of this generation is openness, freedom of self-expression, and orientation to Western progressive culture. The disappearance of the cultural taboo on emotional expression results in a significant increase in the ability to understand and verbalize one's own emotions and feelings. The cohort of 2012 was also a witness to important historical events in their country, namely the Tulip Revolution of 2005 and April Revolution of 2010, which resulted in significant changes in the political system, as well as of social, cultural, and economic conditions.

The cohort of 2018 represents a rapidly developing digital generation where social networks became the main means for self-representation, emotional display and communication. We assume that the absence of alexithymic characteristics relates to the necessity of participants of on-line distant communication to understand and represent their own emotional/psychological state to ensure that their communications are accurately interpreted, suggesting a force compelling an increase in emotional intelligence.

This study reveals no alexithymia in USA young adults and a growing level of emotional self-awareness over all three phases. Individual freedom, extreme individualism, and absence of cultural taboos on free expression of the self are well renowned values and characteristics of American culture. Emotional intelligence training programs have been introduced to secondary and high schools of USA to teach students better understand their emotions and feelings, effectively manage them, and succeed in social communication (Taylor, 
Oberle, Durlak, \& Weissberg, 2017). These programs especially help those students who experience problems with impulse control, anger management, and risk-taking behavior. It might be a common developmental problem for adolescents to recognize their emotions and effectively control them. Teaching students emotion management, emotion vocabulary, active listening, empathy and sharing emotions with other people are core components of emotional intelligence training programs. Similar to the Kyrgyz cohort of 2018, USA cohort of 2018 belongs to generation of informational technologies that may also affect the result.

\section{Conclusion}

This study provides findings for possible link between historical events and components of emotional intelligence, i.e., the ability to be aware of one's own emotions and verbally express them. This study reveals that historical events may shape characteristics of emotional intelligence in young adults. The empirical evidence of gender contributes to an already large body of research finding gender differences in emotional intelligence. This study helps to better understand the influence of generational factors and education on the emotional development of adolescents and young adults from Western and Central Asian cultures.

\section{References}

Ahmetoglu, G., Leutner, F., \& Chamorro-Premuzic, T. (2011). EQ-nomics: Understanding the relationship between individual differences in trait emotional intelligence and entrepreneurship. Personality and Individual Differences, 51(8), 1028-1033.

Ali, O. E. A., Garner, I., \& Magadley, W. (2012). An exploration of the relationship between emotional intelligence and job performance in police organizations. Journal of Police and Criminal Psychology, 27(1), 1-8.

Apaydin, C., \& Anafarta, A. (2012). Factorial validation of the Seven-Component Model of the Work Profile Questionnaire Emotional Intelligence (WPQei) in a Turkish educational setting. Journal of Instructional Psychology, 39(3-4), 159-170.

Ashkanasy, N. M., \& Daus, C. S. (2002). Emotion in the workplace: The new challenge for managers. Academy of Management Executive, 16(1), 76-86.

Austin, E. J., Evans, P., Goldwater, R., \& Potter, V. (2005). A preliminary study of emotional intelligence, empathy and exam performance in first year medical students. Personality and Individual Differences, 39(8), 1395-1405.

Austin, E. J., Saklofske, D. H., \& Egan, V. (2005). Personality, well-being and health correlates of trait emotional intelligence. Personality and Individual Differences, 38(3), 547-558.

Bagby, R. M., Parker, J. D., \& Taylor, G. J. (1994). The Twenty-Item Toronto Alexithymia Scale-I. Item selection and cross-validation of the factor structure. Journal of Psychosomatic Research, 38, 23-32.

Bar-On, R. (August 1996). The era of the "EQ": Defining and assessing emotional intelligence. The 104th Annual Convention of the American Psychological Association, Toronto.

Bechara, A., \& Bar-On, R. (2006). Neurological substrates of emotional and social intelligence: Evidence from patients with focal brain lesions. In J. Cacioppo, P. Visser, and C. Pickett (Eds.), Social neuroscience: People thinking about thinking people (pp. 13-40). Cambridge, MA: MIT Press.

Beins, B. C. (2011). Methodological and Conceptual Issues in Cross-Cultural Research. In K. D. Keith (Ed.), Cross-cultural psychology: contemporary themes and perspectives (pp. 37-55). Wiley-Blackwell, A John Wiley \& Sons, Ltd., Publication.

Blattner, J., \& Bacigalupo, A. (2007). Using emotional intelligence to develop executive leadership and team and organizational development. Consulting Psychology Journal: Practice and Research, 59(3), 209-219.

Bratton, V. K., Dodd, N. G., \& Brown, F. (2011). The impact of emotional intelligence on accuracy of self-awareness and leadership performance. Leadership \& Organization Development Journal, 32(2), 127-149.

Camuffo, A., Gerli, F., \& Gubitta, P. (2012). Competencies matter: Modeling effective entrepreneurship in Northeast of Italy small firms. Cross Cultural Management, 19(1), 48-66.

Cherry, K. (2012). The origins of psychology: A brief history of psychology through the years. Retrieve from https://www.verywell.com/the-origins-of-psychology-2795245

Crowne, K. A. (2013). Cultural exposure, emotional intelligence, and cultural intelligence: An exploratory study. International Journal of Cross Cultural Management, 13(1), 5-22. 
Day, A. L., Therrien, D. L., \& Carroll, S. A. (2005). Predicting psychological health: Assessing the incremental validity of emotional intelligence beyond personality, type a behaviour, and daily hassles. European Journal of Personality, 19(6), 519-536.

Dere, J., Falk, C., \& Ryder, A. (2012). Unpacking cultural differences in alexithymia: The role of cultural values among Euro-Canadian and Chinese-Canadian students. Journal of Cross-Cultural Psychology, 43(8), 1297-1312.

Dion, K. (1996). Ethnolinguistic correlates of alexithymia: Toward a cultural perspective. Journal of Psychosomatic Research, 41, 531-539.

Ekermans, G. (2009). Emotional intelligence across cultures: Theoretical and methodological considerations. In C. Stough, D. Saklofske, and J. Parker (Eds.), Assessing emotional intelligence: Theory, research, and applications (pp. 259-290). New York, NY: Springer.

Ekman, P. (1972). Universals and cultural differences in facial expressions of emotion. In J. Cole (Ed.), Nebraska Symposium on Motivation, 1971, 19, 207-282. Lincoln: University of Nebraska Press.

Emmerling, R. J., \& Boyatzis, R. E. (2012). Emotional and social intelligence competencies: Cross cultural implications. Cross Cultural Management: An International Journal, 19(1), 4-18.

Goleman, D. (1995). Emotional intelligence: Why it can matter more than IQ. New York: Bantam Books.

Goleman, D. (1998). Working with emotional intelligence. New York: Bantam Books.

Güleç, H., Kose, S., Citak, S., \& Yazici, M. (2009). The Turkish version of the 20-Item Toronto Alexithymia Scale (TAS-20): Reliability, validity, and factorial structure. Bulletin of Clinical Psychopharmacology, 19(3), 214-220.

Hofstede, G. (1980). Culture's consequences: International differences in work-related values. Beverly Hills, CA: Sage Publications.

Jausovec, N., \& Jausovec, K. (2010). Emotional intelligence and gender: A neurophysiological perspective. In A. Gruszka, G. Matthews, and B. Szymura (Eds.), Handbook of individual differences in cognition: Attention, memory, and executive control (pp. 109-126). New York, NY: Springer Science + Business Media.

Keats, D., Landa, J. M., Martos, M. P., \& Lopez-Zafra, E. (2010). Emotional intelligence and personality traits as predictors of psychological well-being in Spanish undergraduates. Social Behavior and Personality: An International Journal, 38, 783-794.

Le, H. N., Berenbaum, L. H., \& Raqhavan, C. (2002). Culture and alexithymia: Mean levels, correlates, and the role of parental socialization of emotions. Emotion, 2(4), 341-360.

Mahon, E. G., Taylor, S. N., \& Boyatzis, R. E. (2014). Antecedents of organizational engagement: Exploring vision, mood and perceived organizational support with emotional intelligence as a moderator. Frontiers in Psychology, 5, 1322. doi:10.3389/fpsyg.2014.01322

Matthews. G., Zeidner, M., \& Roberts, R. (2002). Emotional intelligence: Science and myth. Cambridge, MA: MIT Press.

Mayer, J. D., \& Salovey, P. (1997). What is emotional intelligence? In P. Salovey and D. Sluyter (Eds.), Emotional development and emotional intelligence: Implications for educators (pp. 3-31). New York: Basic Books.

Mayer, J. D., Salovey, P., \& Caruso, D. R. (2000). Models of emotional intelligence. In R. J. Sternberg (Ed.), Handbook of intelligence (pp. 396-420). New York: Cambridge.

Mayer, J. D., Salovey, P., \& Caruso, D. R. (2008). Emotional intelligence: New ability or eclectic traits? American Psychologist, 63(6), 503-517.

Meza-Concha, N., Arancibia, M., Salas, F., Behar, R., Salas, G., Silva, H., \& Escobar, R. (2017). Towards a neurobiological understanding of alexithymia. Medwave, 17(4), e6960.

Miao, C., Humphrey, R. H., \& Qian, S. (2017). Are the emotionally intelligent good citizens or counterproductive? A meta-analysis of emotional intelligence and its relationships with organizational citizenship behavior and counterproductive work behavior. Personality and Individual Differences, 116, 144-156.

Momm, T., Blickle, G., Liu, Y., Wihler, A., Kholin, M., \& Menges, J. I. (2015). It pays to have an eye for emotions: Emotion recognition ability indirectly predicts annual income. Journal of Organizational Behavior, 36(1), 147-163.

Nauen, M. S. (2006). Метод когортного анализа в социологии [The method of cohort analysis in sociology]. The Journal of Sociology and Social Anthropology, 9(3), 137-144.

Neimah, J. C., Freyberg, H., \& Sifneos, P. E. (1976). Alexithymia: A view of the psychosomatic process. In O. W. Hill (Ed.), Modern Trends in Psychosomatic Medicine, 3, 430-439. London: Butterworths.

O’Boyle, E. H., Jr., Humphrey, R. H., Pollack, J. M., Hawver, T. H., \& Story, P. A. (2011). The relation between emotional intelligence and job performance: A meta-analysis. Journal of Organizational Behavior, 32(5), 788-818. 
Parker, J. D. A., Taylor, G. J., \& Bagby, R. M. (1998). Alexithymia: Relationship with ego defense and coping styles. Comprehensive Psychiatry, 39, 91-98.

Parker, J. D., Taylor, G. J., \& Bagby, R. M. (2001). The relationship between emotional intelligence and alexithymia. Personality and Individual Differences, 30, 107-115.

Parker, J. D. A., Taylor, G. J., \& Bagby, R. M. (2003). The 20-Item Toronto Alexithymia Scale: III. Reliability and factorial validity in a community population. Journal of Psychosomatic Research, 55, 269-275.

Parker, J. D., Summerfeldt, L. J., Hogan, M. J., \& Majeski, S. (2004). Emotional intelligence and academic success: Examining the transition from high school to university. Personality and Individual Differences, 36, 163-172.

Rolls, E. (2008-11-27). A neurobiological approach to emotional intelligence. In G. Matthews, M. Zeidner, and R. Roberts (Eds.), The science of emotional intelligence: Knowns and unknowns. Oxford: Oxford University Press. Retrieved from https://www.oxfordscholarship.com/view/10.1093/acprof:oso/9780195181890.001.0001/acprof-9780195181890-chapter-3

Rosenblum, G., \& Lewis, M. (2006). Emotional development in adolescence. In G. Adams and M. Berzonsky (Eds.), Blackwell handbook of adolescence (pp. 269-289). doi:10.1002/9780470756607

Ryder, N. (1965). The cohort as a concept in the study of social change. American Sociological Review, 30, 843-861.

Saklofske, D. H., Austin, E. J., Mastoras, S. M., Beaton, L., \& Osborne, S. E. (2012). Relationships of personality, affect, emotional intelligence and coping with student stress and academic success: Different patterns of association for stress and success. Learning and Individual Differences, 22, 251-257.

Salovey, P., \& Mayer, J. D. (1989/1990). Emotional intelligence. Imagination, Cognition, and Personality, 9, $185-211$.

Tarasuik, J. C., Ciorciari, J., \& Stough, C. (2009). Understanding the neurobiology of emotional Intelligence. In C. Stough, D. Saklofske, and J. Parker (Eds.), Assessing emotional intelligence: Theory, research, and applications (pp. 307-320). New York, NY: Springer.

Taylor, G. J., Bagby, R. M., \& Parker, J. D. (1997). Disorders of affect regulation: alexithymia in medical and psychiatric illness. New York, NY: Cambridge University Press.

Taylor, R., Oberle, E., Durlak, J., \& Weissberg, R. (2017). Promoting positive youth development through school-based social and emotional learning interventions: A meta-analysis of follow-up effects. Child Development, 88(4), 1156-1171. 